\title{
SISTEM PENDUKUNG KEPUTUSAN PENENTUAN PENERIMA BANTUAN RUMAH SEHAT LAYAK HUNI MENGGUNAKAN METODE SAW DI DESA PASIR EMAS KECAMATAN SINGINGI
}

\author{
Yulisman $^{1}$, Anita Febriani ${ }^{2}$ \\ ${ }^{1}$ Sistem Infomasi, STMIK Hang Tuah Pekanbaru \\ ${ }^{2}$ Teknik Informatika, STMIK Hang Tuah Pekanbaru \\ Jl. Mustafa Sari No. 5 Tangkerang Selatan, Pekanbaru - Riau \\ e-mail :yulismanaziera27@gmail.com
}

\begin{abstract}
ABSTRAK
Perkembangan dan penerapan teknologi informasi telah banyak membantu aktivitas manusia sehari-hari, diantaranya adalah dalam pengambilan keputusan, baik untuk kepentingan pribadi, organisasi, dan institusi/perusahaan. Sistem Pendukung Keputusan (SPK) telah banyak diterapkan dalam aktivitas manusia, terutama dalam penentuan penerima bantuan rumah sehat layak huni (RSLH) di Desa Pasir Emas, Kecamatan Singingi, Kabupaten Singingi, Provinsi Riau. Selama ini proses penilaian penentuan penerima bantuan rumah sehat layak huni tersebut belum sesuai dengan kriteria dan hanya berdasarkan laporan Ketua Rukun Tetangga (RT), laporan tetangga, dan perkiraan saja, tanpa dilengkapi data pendukung yang valid. Sistem Pendukung Keputusan ini dirancang untuk mendapatkan suatu keputusan dalam menentukan calon penerima penerima bantuan rumah sehat layak huni dengan metode SAW (Simple Additive Weighting). Model metode pembuatan atau pengembangan sistem yang digunakan adalah model waterfall dan perancangan sistem dengan UML. Pembuatan dan pengkodingan sistem menggunakan bahasa pemrograman PHP, dan basis data adalah MySQL serta untuk pengujian sistem dengan motede white box. Hasil penelitian ini bahwa sistem memudahkan aparat desa dalam proses penilaian untuk menentukan penerima bantuan rumah sehat layak huni dan sesuai dengan kriteria. Sistem ini dapat memberikan beberapa kelebihan dibandingkan dengan sistem yang sedang berjalan saat ini, seperti pada saat menentukan penerima bantuan lebih cepat.
\end{abstract}

Kata kunci : Sistem Pendukung Keputusan, Bantuan Rumah Sehat Layak Huni, SAW, PHP, MySQL

\begin{abstract}
The development and application of information technology has helped many everyday human activities, including in decision making, both for personal, organizational, and institutional/corporate interests. Decision Support System (DSS) has been widely applied in human activities, especially in the determination of beneficiaries for live in healthy homes (RSLH) in Pasir Emas Village, Singingi District, Singingi Regency, Riau Province. All this time, the process of evaluating the determination of beneficiaries of healthy housing is not in accordance with the criteria and is only based on reports from the Head of the Neighborhood Association (RT), neighbor reports, and estimates, without valid supporting data. This Decision Support System is designed to obtain a decision in determining the prospective recipients of beneficiary healthy housing assistance with the SAW (Simple Additive Weighting) method. The model of making or developing system method used is the waterfall model and system design with UML. Making and coding the system using the PHP programming language, and the database is MYSQL and for testing the system with the white box method The results of this study that the system makes it easy for village officials in the assessment process to determine beneficiaries of healthy housing that is habitable and in accordance with the criteria. This system can provide several advantages compared to the system currently running, such as when determining the recipient of assistance faster.
\end{abstract}

Keywords : Decision Support System, Assistance for Healthy Living House, SAW, PHP, MySQL 
IN F O R M A T I A

Jurnal Informatika, Manajemen dan Komputer, Vol. 12 No. 1, Mei 2020

eISSN : 2580-3042

pISSN : 1979-0694

\section{PENDAHULUAN}

Sebuah sistem menjadi bagian terpenting di setiap aktivitas dan kegiatan manusia sehari-hari dan manusia tidak bisa terlepas dari lingkup sebuah sistem, baik sistem yang nyata maupun yang abstrak. Sistem menurut O'Brian diartikan sebagai suatu kumpulan atau himpunan dari unsur, komponen, atau variabel yang terorganisir, saling berinteraksi, saling tergantung satu sama lain, dan terpadu (Anggoro, Sriyana, Yuliyanto, \& Widodo, 2015). Berbagai sistem banyak diterapkan dalam aktivitas manusia, termasuk dalam mengambil atau menentukan suatu keputusan. Keputusan merupakan penentuan akhir dari suatu permasalahan yang ditinjau dari berbagai sisi aktivitas manusia dengan memperhatikan saran dan kritik dari stakeholder yang hasilnya bermanfaat bagi kepentingan bersama. Pengambilan suatu keputusan sering digunakan untuk kepentingan suatu organisasi, institusi atau keputusan yang ambil untuk kepentingan pribadi tergantung lingkup permasalahan yang dihadapi.

Suatu keputusan diambil atau ditetapkan, tentunya ada sistem yang menjadi pendukung keputusan yang disebut dengan Sistem Pendukung Keputusan (SPK). Sistem Pendukung Keputusan sering diterapkan untuk kepentingan proses bisnis suatu organisasi atau institusi. Menurut Mc Leod Sistem pendukung keputusan adalah sistem yang menghasilkan informasi dan ditujukan pada suatu masalah tertentu yang harus dipecahkan oleh seorang pimpinan dan dapat membantu pimpinan dalam pengambilan keputusan (Eniyati, 2011). Sistem pendukung keputusan juga dimanfaatkan oleh institusi pemerintah dalam aktivitas perkerjaan seharihari, baik aktivitas di perkantoran maupun dilapangan. Banyak permasalahan pemerintah yang bisa dibantu penyelesaiannya dengan sistem pendukung keputusan dan hasil keputusan tersebut bisa bermanfaat untuk kepentingan kesejahteraan masyarakat.

Salah satu permasalahan yang bisa diterapkannya sistem pendukung keputusan oleh pemerintah yaitu dalam pemilihan penerima Bantuan Rumah Sehat Layak Huni (RSLH). Rumah adalah bangunan gedung yang berfungsi sebagai tempat tinggal yang layak huni, sarana pembinaan keluarga, cerminan harkat dan martabat penghuninya, serta aset bagi pemiliknya (UU RI No. 1 Th. 2011, 2011). Rumah sebagai salah satu kebutuhan pokok manusia yang harus lebih diperhatikan karena menyangkut dengan tempat tinggal yang menjadi salah satu faktor kesejahteraan masyarakat. Kebutuhan akan rumah layak huni semakin meningkat, namun tidak seiring dengan meningkatnya taraf hidup masyarakat ekonomi lemah yang mengharuskan hidup dalam rumah yang tidak layak huni. Bantuan Rumah Sehat Layak Huni (RSLH) yang merupakan program pemerintah Kabupaten Kuantan Singingi berupa bantuan dana untuk perbaikan rumah yang tidak layak huni. Bantuan RSLH ini harus tepat sasaran kepada penduduk tidak mampu yang memenuhi kriteria-kriteria sebagai syarat penerima bantuan RSLH, sehingga penduduk tidak mampu penerima bantuan RSLH dapat menerima bantuan tersebut.

Saat ini proses penilaian penentuan penerima bantuan rumah sehat layak huni tersebut belum sesuai dengan kriteria-kriteria yang sesuai dengan kondisi pemohon yang sebenarnya, dan hanya berdasarkan laporan Ketua Rukun Tetangga (RT), laporan tetangga pemohon, dan perkiraan saja, tanpa dilengkapi data pendukung yang valid, sehingga banyak pemohon yang tidak lulus seleksi pada saat pengajuan bantuan. Penentuan layak tidaknya untuk menerima batuan tersebut, seorang pemohon harus memenuhi kriteria yang telah ditentukan yaitu dari lama berdomisili di desa/kelurahan, usia, tanggungan keluarga, status perkawinan, pekerjaan, kesehatan, kepemilikan rumah, kepemilikan tanah, penghasilan dan kondisi rumah (bangunan) yang meliputi kondisi luas ruangan, kondisi jenis lantai, kondisi jenis atap, kondisi jenis dindig/tembok rumah dan kriteria-kriteria lainnya yang menjadi penilaian. Proses penilainan dan penentuan penerima bantuan masih mengalami kesulitan dalam pengolahan data pemohon bantuan menggunakan cara manual komputerisasi, dengan aplikasi pengolah angka dan pengolah kata sehingga memungkinkan terjadinya rangkap data juga terjadinya kesalahan dari pemohon/penduduk, sedangkan data yang proses dan diolah banyak dan membutuhkan ketelitian, dan kecermatan agar tidak terjadi kesalahan dalam penerima bantuan RSLH.

Berdasarkan permasalahan tersebut maka Sistem Pendukung Keputusan (SPK) bisa diterapkan dalam proses penilaian untuk menentukan penerima bantuan Rumah Sehat Layak Huni (RSLH) yang sesuai dengan kriteria yang telah di tetapkan oleh pemerintah Kabupaten Kuantan Singingi. Model metode yang digunakan dalam pengambilan keputusan) yaitu model metode Simple Additive Weighting (SAW) untuk mengevaluasi alternatif penerimaan bantuan Rumah sehat layak huni sesuai dengan kriteria yang telah ditetapkan. Metode Simple Additive Weighting (SAW) sering juga dikenal 
IN F O R M A T I A

Jurnal Informatika, Manajemen dan Komputer, Vol. 12 No. 1, Mei 2020

eISSN : 2580-3042

pISSN : 1979-0694

sebagai metode penjumlahan terbobot. Konsep dasar metode SAW adalah mencari penjumlahan terbobot dari rating kinerja pada setiap alternatif pada semua atribut. Metode SAW membutuhkan proses normalisasi matriks keputusan (X) ke suatu skala yang dapat diperbandingkan dengan semua rating alternatif yang ada. (Setiaji, 2012)

Berkaitan dengan permasalah penelitian ini pernah dilakukan oleh peneliti sebelumnya yang menghasilkan informasi alternatif keputusan untuk pemilihan penerima bantuan rumah tidak layak huni dengan memberikan skor nilai tertinggi berdasarkan perhitungan dari nilai kriteria-kriteria pada Dinas Perumahan Rakyat dan Kawasan Permukiman Provinsi Kepulauan Bangka Belitung secara cepat, efisien dan efektif (Sugihartono, Ardiansyah, \& Zakky, 2018). Penelitian tentang sistem pendukung keputusan yang lain mendapatkan hasil penelitianya berupa urutan penerima bantuan perbaikan rumah dari yang paling layak sampai yang paling tidak layak dan sistem juga dapat mengkalkulasikan dan menampilkannya dalam bentuk grafik yang mudah dipahami (Salim, 2018). Penelitian yang berkaitan berikutnya sistem pendukung keputusan menghasilkan nilai atau bobot tertinggi yang menunjukkan kalau penduduk tersebut layak mendapatkan bantuan rumah tak layak huni ini (Mardiati \& Oktafianto, 2017).

\section{METODOLOGI PENELITIAN}

Metodologi penelitian merupakan tahapan yang penting dalam suatu penelitian, dengan metode penelitian, tujuan dan hasil penelitian akan terarah sesuai yang diharapkan oleh peneliti. Metode penelitian dalam bidang ilmu komputer dituangkan dalam sebuah model yang akan menjadi acuan peneliti dalam membangun atau mengembangan sebuah sistem atau perangkat lunak. Model metode yang digunakan peneliti dalam penelitian ini adalah pengembangan sistem model waterfall. Berikut model waterfall menurut Sommerville, 2011:

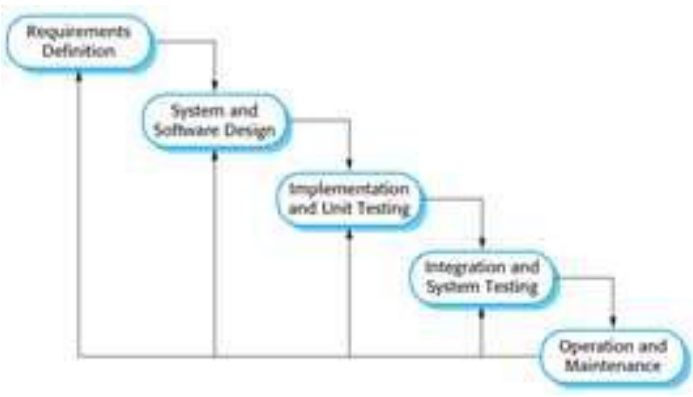

Gambar 1. Model Metode Waterfall (Sommerville, 2011)

Berdasarkan gambaran model waterfall di atas peneliti melakukan pembuatan dan pengembangan Sistem Pendukung Keputusan (SPK) penentuan penerima bantuan rumah sehat layak huni (RSLH), berikut tahapannya:

a. Definisi Persyaratan (Requirements Definition)

Definisi persyaratan merupakan tahap awal dari pembuatan dan pengembangan Sistem Pendukung Keputusan (SPK) penentuan penerima bantuan rumah sehat layak huni (RSLH). Tahapan ini peneliti memulai melakukan analisa kebutuhan dan menggali informasi sebanyak-banyaknya dari user untuk mengembangkan sebuah sistem yang bisa melakukan tugas sesuai yang di inginkan user.

Proses yang dilakukan peneliti dalam memperoleh informasi yang lengkap untuk pembuatan dan pengembangan sistem pendukung keputusan ini, peneliti menggunakan beberapa teknik pengumpulan data, diantaranya sebagai berikut :

1. Pengamatan langsung (observasi), pengamatan langsung ini dilakukan peneliti ingin mengetahui kondisi sistem penentuan bantuan rumah sehat layak huni yang sedang berjalan. Pengamatan ini di mulai dari peneliti langsung pada kantor Desa Pasir Emas Kecamatan Singingi dan juga melihat kondisi masyarakat Desa Pasir Emas, baik yang sudah mendapatkan bantuan maupun calon penerima bantuan.

2. Wawancara, peneliti melakukan tanya jawab dan berkomunikasi secara langsung kepada kepala desa, karyawan kantor Desa Pasir Emas Kecamatan Singingi dan peneliti juga melakukan tanya jawab kepada tokoh masyarakat lainnya salah satunya Ketua Rukun Tetangga (RT) serta masyarakat yang telah menerima atau calon penerima bantuan.

3. Studi pustaka, teknik ini dilakukan peneliti untuk memperoleh teori pendukung penelitian dengan mempelajari buku-buku, artikel dan sumber lain yang ada kaitannya dengan permasalahan penelitian.

b. Perancangan Sistem dan Perangkat Lunak (System and Software Design)

Perancangan Sistem dikerjakan setelah definisi persyaratan sistem selesai dikumpulkan secara lengkap. Perancangan 
INFORMA TIK

Jurnal Informatika, Manajemen dan Komputer, Vol. 12 No. 1, Mei 2020

eISSN : 2580-3042

pISSN : 1979-0694

Sistem adalah sekumpulan aktivitas yang menggambarkan secara rinci bagaimana sistem akan berjalan. Hal itu bertujuan untuk menghasilkan produk perangkat lunak yang sesuai dengan kebutuhan (Sukamto \& Shalahuddin, 2014). Perancangan sistem pendukung keputusan (SPK) penentuan penerima bantuan rumah sehat layak huni (RSLH) peneliti mulai dari merancang perangkat keras dan perangkat lunak pendukung yang sesuai, agar nantinya pengguna tidak mengalami kendala dalam menggunakan sistem. Berikutnya peneliti melakukan analisis dan perancangan data masukan dan keluaran.

1. Data Masukan (Input Data)

Data masukan (input data) terdiri dari nilai, bobot, kriteria dan alternatif (Calon Penerima Bantuan).

2. Data Keluaran (Output Data)

Data keluaran yang dihasilkan oleh sistem berupa tabel yang menampilkan laporan. Data-data yang ada pada tabel tersebut adalah data hasil akhir yang dikeluarkan oleh program yang berasal dari nilai setiap kriteria.

Setelah analisis dan perancangan data ditentukan, selanjutnya peneliti melakukan analisis pengguna sistem yang akan terlibat langsung dengan aktivitas sistem. Pengguna yang akan menggunakan sistem sistem pendukung keputusan (SPK) penentuan penerima bantuan rumah sehat layak huni (RSLH) adalah Admin dan Kepala Desa pada Desa Pasir Emas, tujuan penggunaannya yaitu membantu aparat desa dalam menentukan penerima bantuan rumah sehat layak huni di Desa Pasir Emas. Admin melakukan pengelolaan data kriteria, data user, data alternatif dan data nilai, serta melakukan pencetakan laporan. Kepala desa hanya dapat melihat hasil dari penilaian.

Langkah berikutnya peneliti melakukan pemodelan sistem secara umum atau perancangan sistem secara umum. Perancangan ini dilakukan atau bertujuan memberikan gambaran secara umum kepada pengguna terhadap sistem yang baru nanti. Sebelum melangkah lebih jauh mari kita lihat dulu Sistem Pendukung Keputusan Untuk Menentukan Penerima Bantuan Rumah sehat layak huni di Desa Pasir Emas ini, yang membutuhkan data kriteria (Ci) dan bobot (Wj) sebagai berikut :

Tabel 1. Kriteria dan Bobot

\begin{tabular}{|l|l|r|l|}
\hline No & Kriteria & Bobot & Ket \\
\hline 1 & Luas Ruangan & $10 \%$ & Benefit \\
\hline 2 & Kondisi DInding & $5 \%$ & Benefit \\
\hline 3 & Kondisi Atap & $5 \%$ & Benefit \\
\hline 4 & Kondisi Lantai & $5 \%$ & Benefit \\
\hline 5 & Usia & $5 \%$ & Benefit \\
\hline 6 & Kepemilikan Tanah & $10 \%$ & Benefit \\
\hline 7 & Tanggungan Keluarga & $10 \%$ & Benefit \\
\hline 8 & Penghasilan & $10 \%$ & Benefit \\
\hline 9 & Lama Bedomisili & $5 \%$ & Benefit \\
\hline 10 & Status Perkawinan & $5 \%$ & Benefit \\
\hline 11 & Pekerjaan & $5 \%$ & Benefit \\
\hline 12 & Kesehatan & $10 \%$ & Benefit \\
\hline 13 & Kepemilikan Rumah & $10 \%$ & Benefit \\
\hline
\end{tabular}

Lanjut ke nilai alternatif kriteria, berikut tabel nya:

Berikut 9 alternatif yang dijadikan kasus yaitu:

A1 = Asli

$\mathrm{A} 2=$ Siti

A3 = Jamari

A4 = Lanjar

Tabel 2. Data Nilai

\begin{tabular}{|c|c|c|c|c|c|c|c|c|c|c|c|c|c|}
\hline $\begin{array}{c}\text { Nama } \\
\text { Pemohon }\end{array}$ & C1 & C2 & C3 & C4 & C5 & C6 & C7 & C8 & C9 & C10 & C11 & C12 & C13 \\
\hline Asli & 3 & 3 & 3 & 1 & 2 & 1 & 2 & 1 & 1 & 1 & 3 & 2 & 1 \\
\hline Siti & 3 & 2 & 2 & 3 & 2 & 1 & 2 & 1 & 1 & 1 & 2 & 2 & 1 \\
\hline Jamari & 2 & 2 & 3 & 3 & 1 & 2 & 2 & 2 & 2 & 2 & 2 & 2 & 2 \\
\hline Lanjar & 2 & 3 & 2 & 2 & 1 & 1 & 2 & 2 & 1 & 1 & 1 & 2 & 1 \\
\hline
\end{tabular}

Setelah data nilai dikumpulkan selanjutanya data tersbut di normalisasikan, seperti telihat pada tabel 3 berikut:

Tabel 3. Hasil Normalisasi

\begin{tabular}{|c|c|c|c|c|c|c|c|c|c|c|c|c|c|}
\hline $\begin{array}{c}\text { Nama } \\
\text { Pemohon }\end{array}$ & C1 & C2 & C3 & C4 & C5 & C6 & C7 & C8 & C9 & 10 10 & $\begin{array}{c}\text { C } \\
11\end{array}$ & $\begin{array}{c}\text { C } \\
12\end{array}$ & $\begin{array}{c}\text { C } \\
13\end{array}$ \\
\hline Asli & 1 & 1 & 1 & 0,33 & 1 & 0,5 & 1 & 0,5 & 0,5 & 0,5 & 1 & 1 & 0,5 \\
\hline Siti & 1 & 0,67 & 0,67 & 1 & 1 & 0,5 & 1 & 0,5 & 0,5 & 0,5 & 0,67 & 1 & 0,5 \\
\hline Jamari & 0,67 & 0,67 & 1 & 1 & 0,5 & 1 & 1 & 1 & 1 & 1 & 0,67 & 1 & 1 \\
\hline Lanjar & 0,67 & 1 & 0,67 & 0,67 & 0,5 & 0,5 & 1 & 1 & 0,5 & 0,5 & 0,33 & 1 & 0,5 \\
\hline Bobot & 10 & 5 & 5 & 5 & 5 & 10 & 10 & 10 & 5 & 5 & 5 & 10 & 10 \\
\hline
\end{tabular}

Tabel 4. Hasil Akhir

\begin{tabular}{|c|c|c|}
\hline Nama Alternatif & Jumlah & Rank \\
\hline Jamari & 0,86 & 1 \\
\hline Asli & 0,72 & 2 \\
\hline Siti & 0,7 & 3 \\
\hline Lanjar & 0,68 & 4 \\
\hline
\end{tabular}

Tahapan berikutnya melakukan perancangan pemodelan sistem dalam hal ini peneliti menggunakan UML (Unified Modelling Language). UML (Unified Modelling Language) merupakan bahasa standar yang telah ditetapkan dalam industri perangkat lunak dan visualisasi bahasa dalam merancang dan mendokumentasikan aplikasi atau sistem 
IN F O R M A T I A

Jurnal Informatika, Manajemen dan Komputer, Vol. 12 No. 1, Mei 2020

eISSN : 2580-3042

pISSN : 1979-0694

perangkat lunak. UML memberikan suatu standar untuk merancang model suatu aplikasi atau sistem. Notasi UML merupakan sekumpulan simbol khusus untuk menggambarkan berbagai diagram perangkat lunak (Mallu, 2015). Pemodelan sistem yang bangun pada sistem pendukung keputusan ini yaitu model Use Case Diagram, Class Diagram dan Activity diagram, Berikut peracangan pemodelan sistemnya:

1. Use Case Diagram

Perancangan Use Case Diagram dibuat berdasarkan analisa dan pengamatan peneliti dilapangan tetang siapa saja pengguna atau aktor yang berhubungan langsung di sistem, termasuk mendefinisikan fungsi, fitur dan modul yang dapat disediakan oleh sistem. Use Case Diagram menunjukkan hubungan interaksi antar aktor dengan Use case didalam suatu sistem yang bertujuan untuk menentukan bagaimana aktor berinteraksi dengan sebuah sistem (Windarto, 2017). Diagram use case ini juga menjelaskan siapa saja aktor yang dapat login pada sistem, yaitu admin yang dapat login serta dapat melakukan proses penilaian pada sistem. Sedangkan kepala desa juga dapat login namun hanya dapat melihat hasil penilaian. Berikut model Use Case Diagram pada sistem pendukung keputusan penentuan penerima bantuan Rumah Sehat Layak Huni (RSLH):

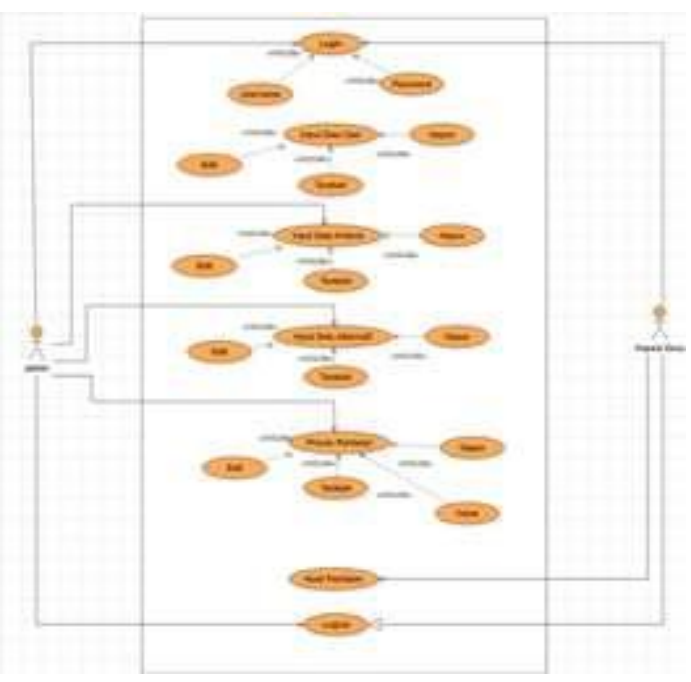

Gambar 2. Use Case Diagram

2. Activity Diagram

Activity diagram (diagram aktivitas) menggambarkan alur atau proses saat pengguna melakukan aktivitas di sistem

sesuai dengan hak akses pengguna pada sistem tersebut. Activity diagram merupakan model khusus yang digambarkan dalam diagram status yang dilengkapi simbol-simbol khusus dan menampilkan aliran penggunaan sistem dengan aktivitas ke aktivitas lainnya dalam suatu sistem (Tridarni, Tasrif, \& Hendriyani, 2015). Berikut beberapa model Activity Diagram pada sistem pendukung keputusan penentuan penerima bantuan Rumah Sehat Layak Huni (RSLH):

a) Aktivitas Login Admin

Aktivitas ini dimulai dari memasukkan (input) Username dan Password sampai sistem menampilkan menu utama admin.

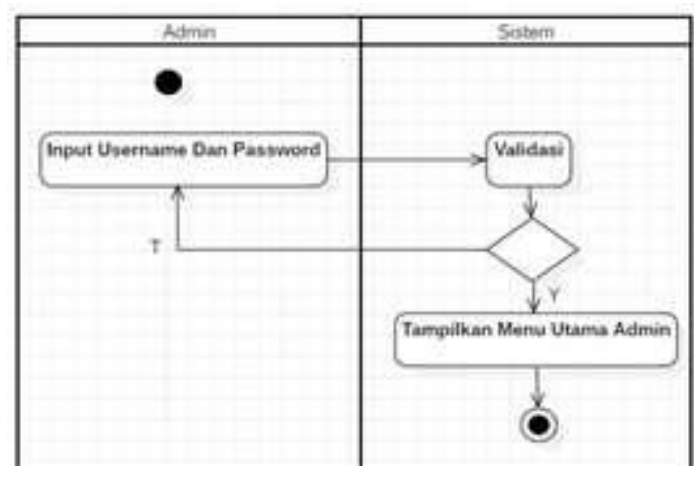

Gambar 3. Diagram Aktivitas Login Admin

b) Aktivitas Login Kepala Desa

Aktivitas login kepala desa angat penting dan merupkan pengambilan keputusan akhir di tingkat kampus. Aktivitas diawali Kepala desa memasukkan (input) Username dan Password dan diakhiri dengan tampilnya menu utama kepala desa.

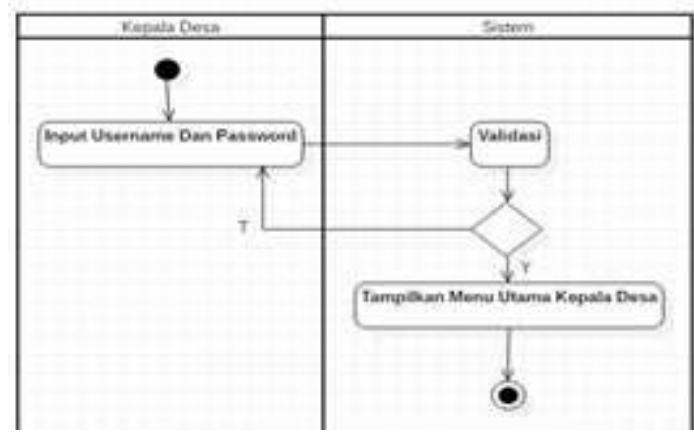

Gambar 4. Diagram Aktivitas Login Kepala Desa 
IN F ORMA T I K A

Jurnal Informatika, Manajemen dan Komputer, Vol. 12 No. 1, Mei 2020

eISSN : 2580-3042

pISSN : 1979-0694

c) Aktivitas Tambah User

Penambahan User dilakukan oleh admin dengan menampilkan menu user, pada tampilan user ini admin juga bisa melakukan mengedit dan menghapus data user, berikut alur aktivitas tambah user:

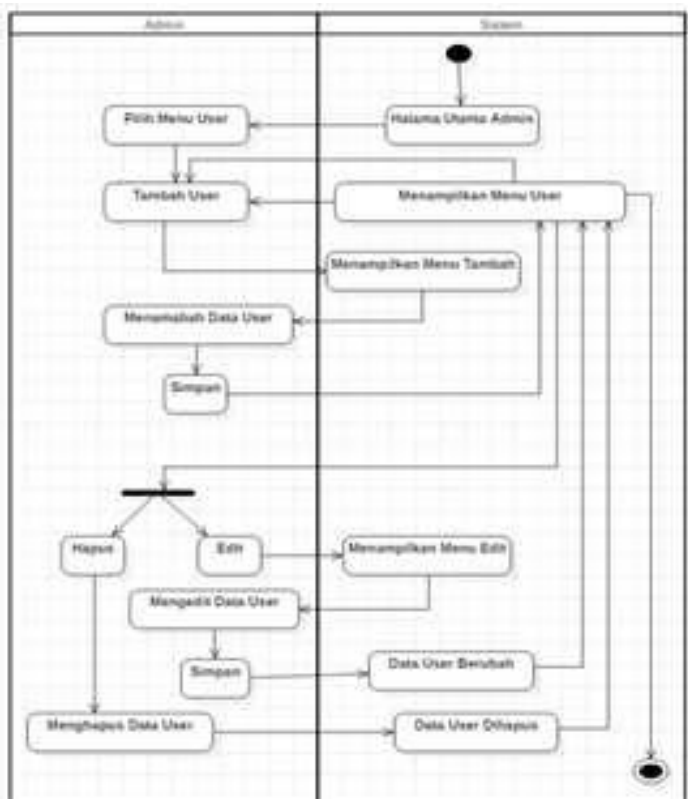

Gambar 5. Diagram Aktivitas Diagram Tambah User

d) Aktivitas Tambah Kriteria

Aktivitas penambahan kriteria dilakukan oleh admin melalui tampilan menu admin.

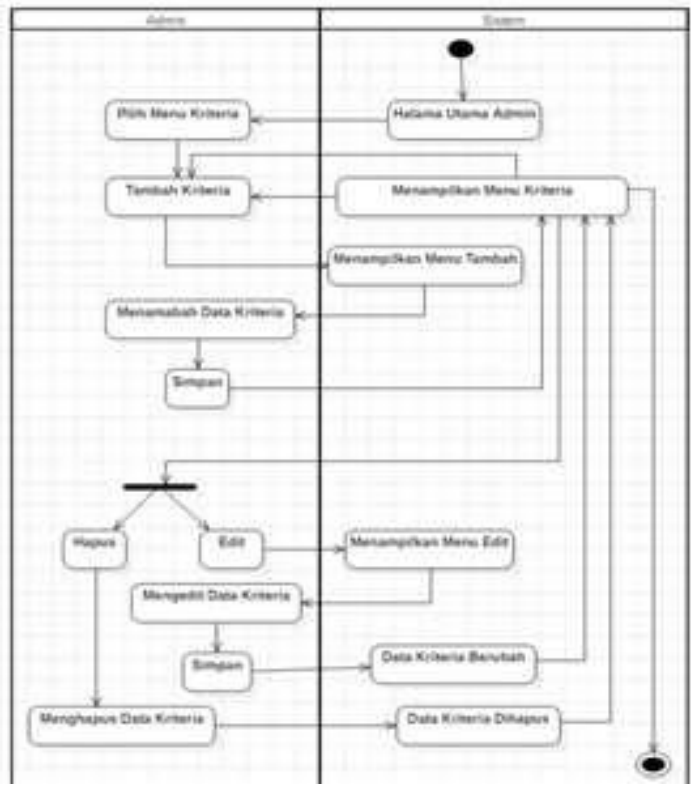

Gambar 6. Diagram Aktivitas Tambah Kriteria

e) Aktivitas Tambah Alternatif

Berikutnya penambahan alternatif juga dilakukan oleh admin dengan melalui login admin, dan alur aktivitasnya sama dengan alur aktivitas sebelumnya.

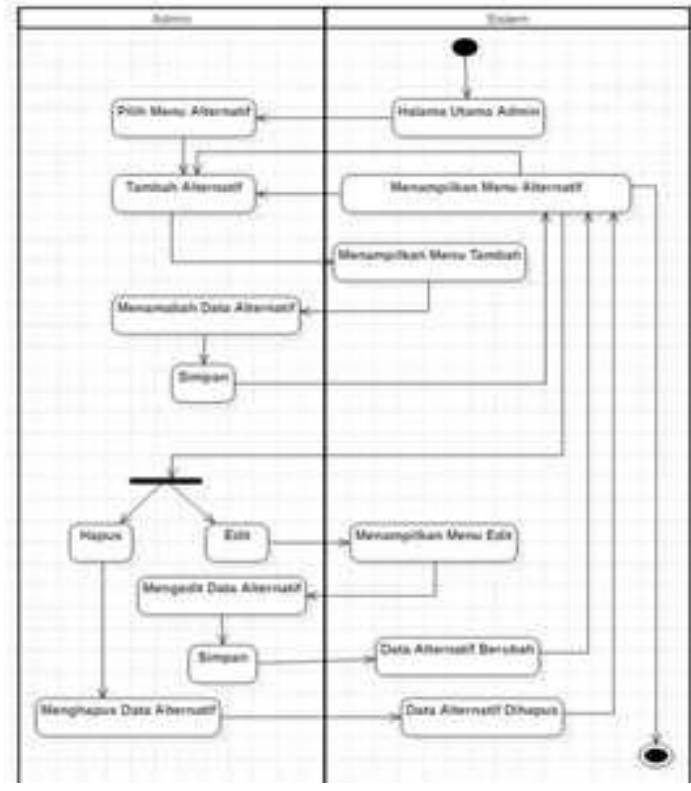

Gambar 7. Diagram Aktivitas Tambah Alternatif

f) Aktivitas Proses Penilaian

Proses penilaian dilakukan juga dilakukan dari login admin, berikut alur aktivitasnya:

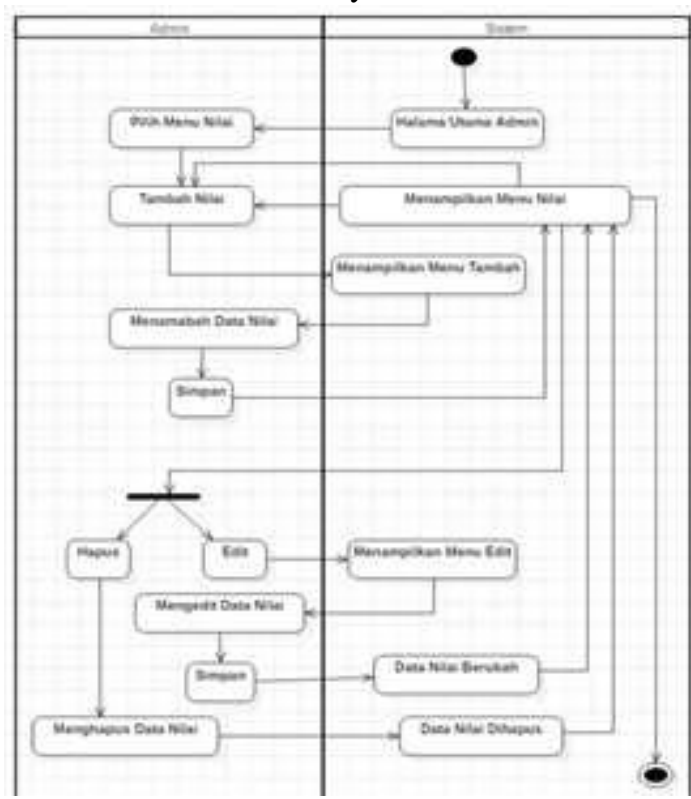

Gambar 8. Diagram Aktivitas Proses Penelaian 
IN F O R M A T I A

Jurnal Informatika, Manajemen dan Komputer, Vol. 12 No. 1, Mei 2020

eISSN : 2580-3042

pISSN : 1979-0694

g) Aktivitas Hasil Penilaian

Hasil penelitian bantuan rumah sehat layak huni ini dapat di lihat dari login kepala desa dan juga bisa admin dan terlihat pada alur aktivitas berikut:

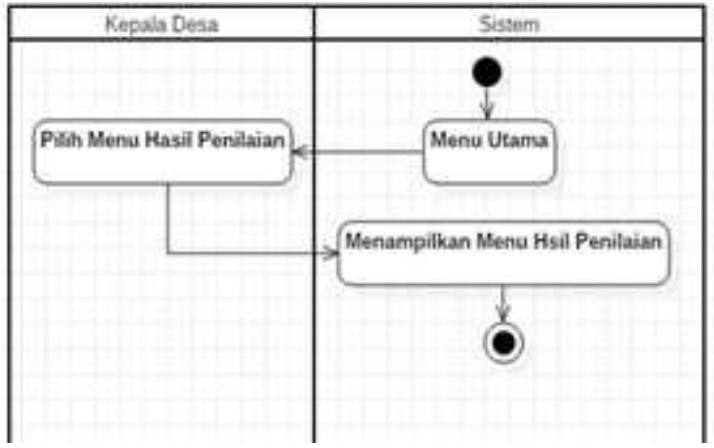

Gambar 9. Diagram Aktivitas Hasil Penilaian

\section{Class Diagram}

Class Diagram (Diagram Kelas) ini berfungsi menjelaskan class-class mana yang akan digunakan untuk melakukan relasi atau hubungan terhadap pemilihan calon penerima bantuan pada aplikasi sistem pendukung keputusan untuk menentukan penerima bantuan umah tidak layak huni. Class Diagram (Diagram Kelas) menggambarkan suatu class yang berhubungan dengan class lainnya dalam sebuah sistem yang sedang dibuat dan bagaimana caranya agar saling dapat berkolaborasi untuk mencapai suatu tujuan (Setyawan \& Sutariyani, 2013). Berikut gambaran class diagram sistem pendukung keputusan bantuan rumah sehat layak huni dibawah ini:

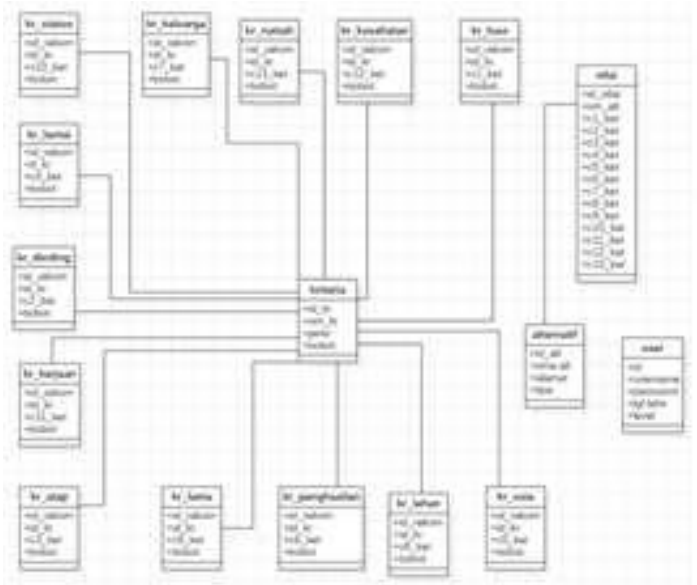

Gambar 10. Diagram Aktivitas Hasil Penilaian
Perancangan berikutnya setelah dilakukan peracangan pemodelan sistem adalah perancangan basis data (database). Menurut Pahlevi basis data (database) adalah sekumpulan data yang saling berhubungan secara logis beserta deskripsinya, yang digunakan secara bersama-sama dan dirancang untuk memenuhi kebutuhan informasi disuatu tempat (Elistri, Wahyudi, \& Supardi, 2014). Pembuatan Sistem Pendukung Keputusan (SPK) penentuan penerima bantuan rumah sehat layak huni (RSLH) berbasis web ini peneliti membuat database dengan nama : saw-bantuan, yang terdiri dari 17 tabel, yaitu tabel alternatif, kriteria, kr_atap, kr_dinding, kr_keluarga, kr_lahan, $\quad k r \_l a n t a i, \quad k r \_l u a s, \quad k r \_u s i a$, kr_penghasilan, $\quad \mathrm{kr}$ _lama, $\mathrm{kr}$ _status, kr_pekerjaan, kr_kesehatan, kr_rumah, nilai, user.

Pembuatan basis data untuk sistem pendukung keputusan ini peneliti menggunakan tool MySQL pada aplikasi XAMPP dan browser Mozilla sebagai aplikasi pendukung tambahan untuk menampilkan basis data dan pengujian sistem. Bahasa pemrograman yang digunakan adalah PHP (Hypertext Preprocessor). PHP (Hypertext Preprocessor) merupakan bahasa pemrograman script server-side yang dirancang untuk pembuatan dan pengembangan aplikasi berbasis web. Proses pengkodingan bahasa pemrograman peneliti menggunakan aplikasi Notepad ++ .

Tahapan perancangan berikutnya peneliti melakukan peracangan tampilan antar muka. Perancangan tampilan antarmuka merupakan salah satu bagian terpenting dalam merancang suatu sistem atau aplikasi. Proses perancangan antarmuka ini, peneliti terfokus pada fungsi-fungsi, elemen-elemen dan objek-objek yang akan memudahkan pengguna dalam menjalankan dan mengoperasikan sistem atau aplikasi. Perancangan antar muka terdiri dari dua jenis, yaitu perancangan form masukan (input design) dan perancangan form keluaran/laporan (output design).

c. Implementasi dan Pengujian Unit (Implementation and Unit Testing)

Implementasi sistem pada tahap ini dengan melakukan pengujian sistem per unit sistem. Sistem akan diuji dengan 
IN F ORM T IK A

Jurnal Informatika, Manajemen dan Komputer, Vol. 12 No. 1, Mei 2020

eISSN : 2580-3042

pISSN : 1979-0694

mengimplemetasikan unit-unit sistem yang telah selesai bangun. Berdasarkan pengujian per unit ini peneliti melakukan evaluasi terhadap sistem, terutama pada modul dan fungsi yang terdapat pada sistem, apakah masih ada terdapat kesalahan dan bug pada pada bahasa pemrograman, yang bisa menyebabkan sistem tidak bisa dijalankan. Berikutnya pengujian terhadap perangkat keras pendukung sistem, yaitu peneliti melakukan pengujian dengan perangkat keras (hardware) dengan spesifikasi minimal dalam pengoperasian sistem.

d. Integrasi dan Pengujian Sistem (Integration and System Testing)

Sistem integrasi atau integrated system merupakan rangkaian yang menghubungkan beberapa sistem bagi secara fisik maupun fungsional. Sistem ini akan menggabungkan komponen sub sistem dalam satu sistem yang menjamin setiap fungsi dapat berfungsi sebagai kesatuan dari sebuah sistem (Berca Hardayaperkasa, 2018). Integrasi sistem merupakan tahapan yang wajib dilakukan, dimana peneliti melakukan penyatuan terhadap bagian dan unsur sistem yang masih terpisah. Integrasi sistem tahap pertama yang dilakukan adalah penyesuaian sistem dengan perangkat pendukung, baik perangkat keras (hardware, seperti koneksi printer dengan sistem, koneksi jaringan lokal, dan perangkat lainnya) maupun perangkat lunak (software, seperti aplikasi XAMPP, browser, aplikasi pdf, dan lain-lain), dan lebih penting lagi integrasi kepada setiap stakeholder yang berkaitan dengan sistem, yaitu melakukan sosialisasi kepada ketua RT dan RW, Kepala Desa dan setiap staf desa yang berhubungan dengan dalam proses pemberian bantuan rumah sehat layak huni, dan juga memberikan pelatihan kepada operator sistem yang dilengkapi dengan panduan penggunaan sistem, sehingga penerapan sistem bisa lebih maksimal lagi.

Integrasi sistem yang peneliti lakukan bersamaan dengan migrasi sistem. Menurut Riyanto Migrasi merupakan proses Perpindahan, yang mana di dalam dunia informasi khususnya database berarti perpindahan data dari satu database ke database yang lain. Migrasi merupakan suatu metode saling berinteraksi yang diterapkan dalam database untuk pemindahan data karena faktor eksternal yang memungkinkan pengguna untuk memindahkan data ke database lain (Bafadal, 2012). Migrasi sistem yang digunakan adalah dengan metode migrasi paralel, dimana sistem yang lama tetap berjalan seperti biasa, bersamaan dengan sistem yang baru. Migrasi ini peneliti memberikan waktu/periode berjalan sistem lama dan sistem baru selama 1 (satu) tahun, dengan selalu melakukan evaluasi terhadap sistem baru, terutama kelemahan-kelemahan sistem baru dari sistem lama dan melakukan perbaikan dari kelemahan tersebut. Setelah periode habis peneliti akan menerapkan sistem baru secara keseluruhan.

Setelah integrasi sistem dilakukan berikutnya adalah pengujian sistem. Pengujian sistem adalah langkah dan bagian yang terpenting dalam pembuatan dan pengembangan sistem, tanpa adanya suatu pengujian, peneliti tidak bisa mengetahui kekurangan sistem dari segi pengguna. Pengujian harus melibatkan pengguna dan seluruh stakeholder yang berhubungan dengan sistem. Pengujian sistem bukan sekedar try and eror, namun memerlukan suatu metode agar tujuan sistem dibuat atau dikembangkan sesuai dengan harapan pengguna. Metode yang peneliti gunakan dalam pengujian adalah white box testing.

Pengujian white box merupakan salah satu cara untuk menguji aplikasi dengan melihat modul dan menganalisa kode dari program yang telah dibuat (Pathy, Panda, \& Baboo, 2015). Salah satu jenis pengujian white box adalah statement coverage yang merupakan sebuah teknik white box yang memastikan setiap executable statements dijalankan satu kali (Mustaqbal, Firdaus, \& Rahmadi, 2015). Perbandingan perhitungan manual dan menggunakan sistem ditunjukkan pada Gambar 11 dan Gambar 12 berikut:

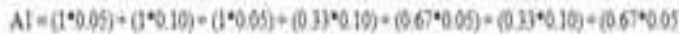

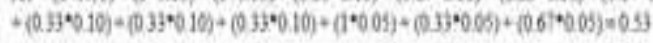

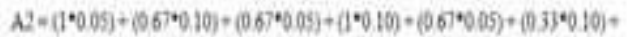

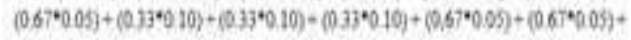
$(033 \times 0.05)=0.53$

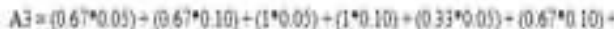

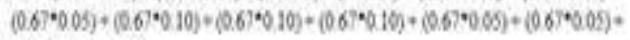
$10670055=067$

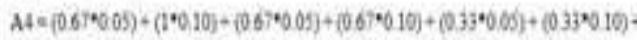

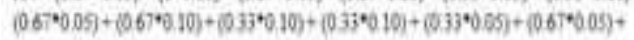
$(033 * 0.05) \times 0.52$

Gambar 11. Gambar Perhitungan Manual 
I N F O R M A T I K A

Jurnal Informatika, Manajemen dan Komputer, Vol. 12 No. 1, Mei 2020

eISSN : 2580-3042

pISSN : 1979-0694

Pada gambar 11 ditampilkan gambar hasil dari perhitungan manual setiap alternatif dengan menggunakan 13 kriteria. Setelah itu, dilakukan pengujian terhadap sistem dengan memasukkan data sesuai dengan data yang digunakan pada proses manual. Hasil perhitungan yang dilakukan oleh sistem dapat dilihat pada gambar 12:

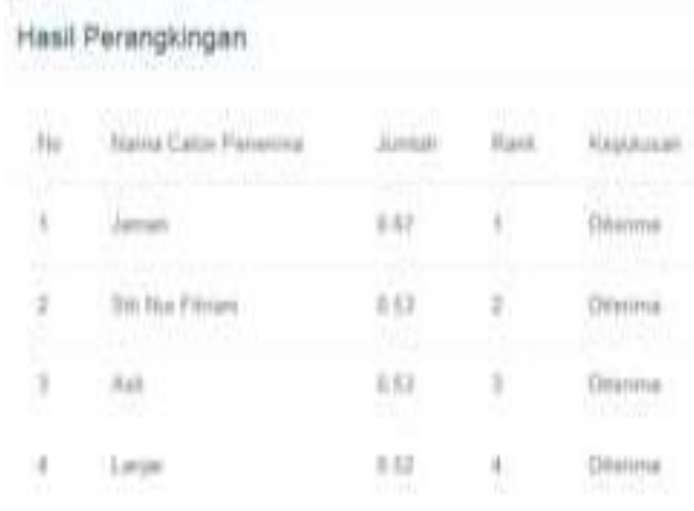

Gambar 12 Perhitungan Menggunakan Sistem

Gambar 12 menampilkan hasil perhitungan dari sistem. Hasil perhitungan tersebut sama dengan hasl perhitungan manual. Berdasarkan white box testing yang telah dilakukan, didapatkan kecocokan hasil $100 \%$ valid. Hal tersebut menandakan bahwa sistem pendukung keputusan bantuan rumah sehat layak huni yang sudah dibuat sudah berjalan dengan baik sesuai dengan fungsi-fungsi yang diharapkan.

e. Pengoperasian dan Perawatan (Operation and Maintenance)

Pengoperasian dilakukan setelah sistem sukses diuji dan diterapkan serta fungsi dari sistem dapat mengakomodasi semua yag diperlukan dan dapat mempercepat dan mempersingkat pemilihan serta menentukan penerima rumah sehat layak huni (RSLH). Proses pengopersian sistem yang tidak kalah pentingnya yaitu keterlibatan setiap stakeholder yang ada di lingkup sistem seperti peran seorang Ketua Rukun Tetangga (RT) lebih dilibatkan, karena semua data akan bersumber dari observasi langsung seorang ketua RT yang selalu berinteraksi ditengahtengah masyarakat. Pengopersian perangkat pendukung sistem lainnya juga dilakukan, sehingga tidak ada yang tidak berfungsi dari sistem.
Proses pengoperasian sistem juga diiringi dengan dengan perawatan sistem. Perawatan dilakukan untuk menjaga agar sistem tidak terjadi kesalahan, baik kesalahan fungsi, kode program, modul, perangkat pendukung lainnya baik software maupun hardware. Perawatan dilakukan berkala, atau ketika sistem tidak dalam aktivitas tinggi. Perawatan juga mencakup pada pengembangan sistem seiring dengan peningkatan kebutuhan pengguna dan perkembangan teknologi informasi.

\section{HASIL DAN PEMBAHASAN}

Hasil merupakan penerapan sistem yang selesai dibangun secara keseluruhan. Tahapan ini juga nanti dilakukan evaluasi dan pembahasan terhadap kekurangan pada sistem jika terjadi kesalahan fungsi, alur program, modul dan lainlain yang menyebabkan sistem tidak berjalan seperti yang diharapkan oleh pengguna, dan proses ini dilakukan sama pada tahapan integrasi dan pengujian sistem (integration and system testing). Berikut tampilan hasil akhir sistem yang telah dibangun:

a. Tampilan login admin

Tampilan awal untuk Login admin ini untuk masuk kedalam sistem, admin harus memasukkan Username dan Password yang telah terdaftar dalam database. Kemudian admin mengklik tombol Login, berikut tampilan form login admin:

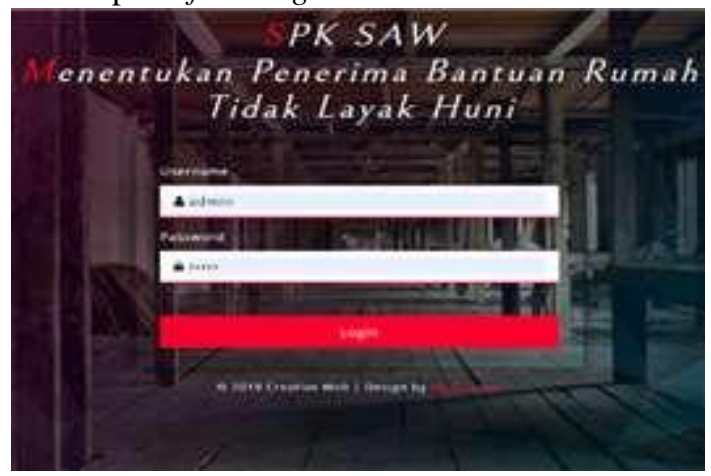

Gambar 13. Form Login Admin

b. Menu Utama Admin

Tampilan Menu Utama pada tampilan admin, yang terdiri dari menu-menu user, menu kriteria, menu alternative dan menu proses penilaian, seperti terlihat pada gambar berikut: 
IN F ORMA T I K A

Jurnal Informatika, Manajemen dan Komputer, Vol. 12 No. 1, Mei 2020

eISSN : 2580-3042

pISSN : 1979-0694



Gambar 14. Form Halaman Utama Admin

c. Tampilan Menu User

Gambar 15 berikut adalah tampilan pada menu user terdapat id, username, nama user, tanggal lahir, level dan informasi ini hanya di peroleh pada login admin. Admin bisa menambahkan dan menghapus user.

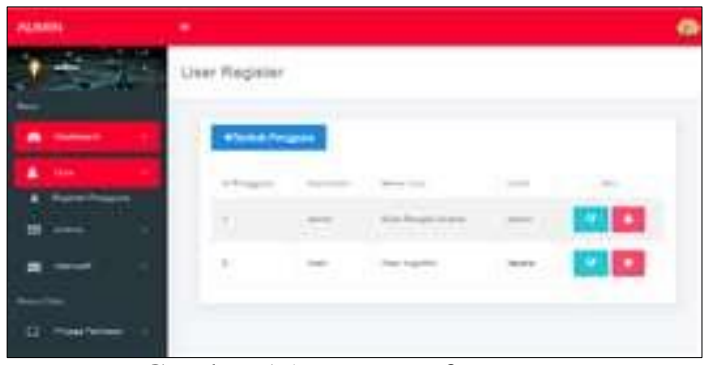

Gambar 15. Form Daftar User

d. Tampilan Menu Kriteria

Tampilan/Form Menu Kriteria yang juga terdapat pada halaman admin terdapat lima field yaitu : id kriteria, nama kriteria, jenis, dan bobot, serta untuk aksi, admin bisa melakukan penambahan dan menghapus kriteria, seperti pada gambar 15 berikut:

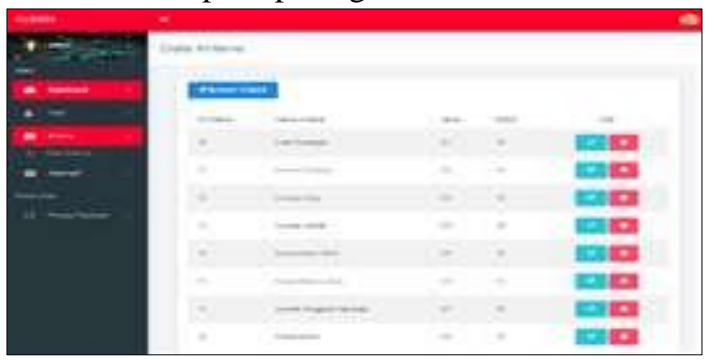

Gambar 16. Form Daftar Kriteria

e. Tampilan Menu Alternatif

Tampilan kriteria terdapat id, nama Alternatif, alamat, tipe dan untuk Aksi sama dengan tampilan yang lain, dimana admin bisa menambah dan menghapus daftar alternatif, berikut tampilannya:

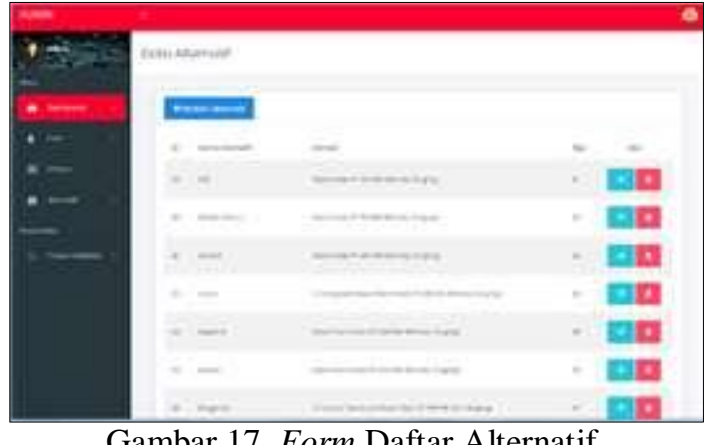

Gambar 17. Form Daftar Alternatif

f. Tampilan Menu Proses Penilaian

Pada menu proses penilaian admin memasukkan id nilai, nama pemohon, alasan pendukung yang akan dipilih serta pemberian nilai pada kriteria $\mathrm{C} 1, \mathrm{C} 2, \mathrm{C} 3, \mathrm{C} 4, \mathrm{C} 5, \mathrm{C} 6$, C7, C8 dan aksi, berikut tampilan menu proses penilaian:

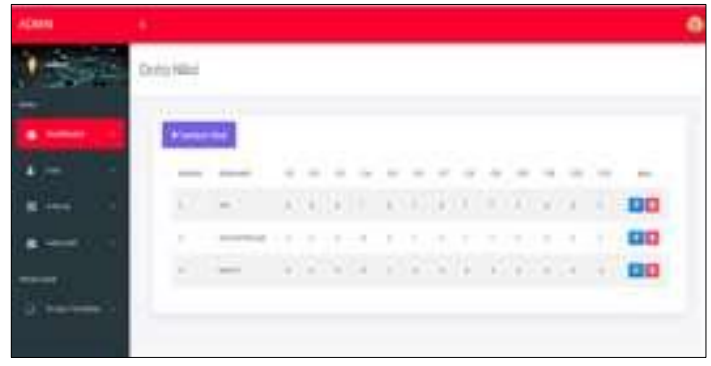

Gambar 18. Form Proses Penilaian

g. Tampilan Menu Hasil Penilaian

Hasil penilaian yang telah dinilai juga terdapat di halaman admin dan di proses oleh admin pada menu proses penilaian terdapat hasil rating kecocokan, normalisasi dan hasil perangkingan, seperti yang terlihat pada gambar berikut:

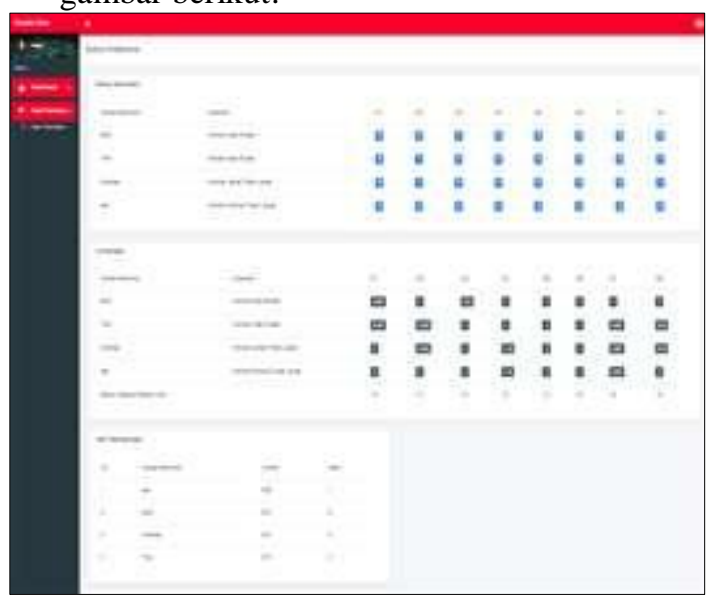

Gambar 18. Form Hasil Penilaian 
IN F ORM T IK A

Jurnal Informatika, Manajemen dan Komputer, Vol. 12 No. 1, Mei 2020

eISSN : 2580-3042

pISSN : 1979-0694

h. Laporan

Laporan penerima batuan ditampilkan dalam format laporan bulanan dan tahunan dalam satu laporan, berikut tampilannya:

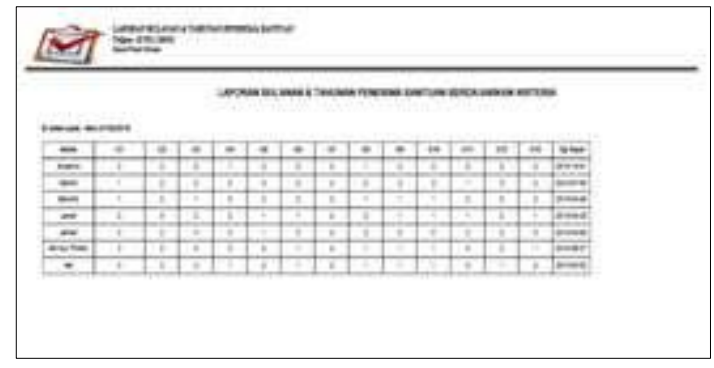

Gambar 19. Form Laporan

\section{KESIMPULAN}

Berdasarkan hasil dan pembahasan penelitian tentang Sistem Pendukung Keputusan Untuk Menentukan Penerima Bantuan Rumah sehat layak huni di Desa Pasir Emas Kecamatan Singingi Kabupaten Kuantan Singingi dapat diperoleh kesimpulan, bahwa Sistem Pendukung Keputusan Untuk Menentukan Penerima Bantuan Rumah sehat layak huni di Desa Pasir Emas Kecamatan Singingi. membantu pihak desa dalam menentukan masyarakat penerima bantuan rumah layak huni melalui data perangkingan dari hasil yang telah diolah dalam sistem tersebut.

Aplikasi yang dirancang adalah Sistem Pendukung Keputusan Untuk Menentukan Penerima Bantuan Rumah sehat layak huni di Desa Pasir Emas Kec. Singingi. Aplikasi ini dapat memberikan beberapa kelebihan dibandingkan dengan sistem yang sedang berjalan saat ini, seperti pada saat memproses data masyarakat untuk menentukan penerima bantuan lebih cepat.

\section{REFERENSI}

Anggoro, Y. D., Sriyana, Yuliyanto, A. T., \& Widodo, W. L. (2015). Analisis dan Perancangan Sistem Informasi Energi Nuklir. Jurnal Pengembangan Energi Nuklir, Vol. 17(No.1), 45-55.

Bafadal, M. M. (2012). Migrasi basisdata pada sistem informasi akademik universitas tanjungpura. Jurnal Ilmiah SISFOTENIKA, Vol. 2(No. 2), 71-80. https://doi.org/10.30700/jst.v2i2

Berca Hardayaperkasa. (2018). Keuntungan Menggunakan Sistem Integrasi bagi Perusahaan Anda. Retrieved January 29, 2019,

from

https://www.berca.co.id/index.php/blog/ite $\mathrm{m} / 98$-keuntungan-menggunakan-sistemintegrasi-bagi-perusahaan-anda

Elistri, M., Wahyudi, J., \& Supardi, R. (2014). Penerapan Metode SAW dalam Sistem Pendukung Keputusan Pemilihan Jurusan pada Sekolah Menengah Atas Negeri 8 Seluma. Jurnal Media Infotama, Vol. 10(No. 2), 105-109.

Eniyati, S. (2011). Perancangan Sistem Pendukung Pengambilan Keputusan untuk Penerimaan Beasiswa dengan Metode SAW (Simple Additive Weighting). Jurnal Teknologi Informasi DINAMIK, Vol. 16(No. 2), 171-177.

Mallu, S. (2015). Sistem Pendukung Keputusan Penentuan Karyawan Kontrak Menjadi Karyawan Tetap Menggunakan Metode Topsis. Jurnal Ilmiah Teknologi Informasi Terapan, Vol. I(No. 2), 36-42.

Mardiati, K. S., \& Oktafianto. (2017). Sistem Pendukung Keputusan (DSS) Penerima Bantuan Rumah Tak Layak Huni (RTLH) pada Kecamatan Ambarawa dengan Menggunakan Metode Analytical Hierarcy Process (AHP). In Konferensi Mahasiswa Sistem Informasi (Vol. Vol. 5, pp. 302308). Retrieved from http://ojs.stmikpringsewu.ac.id/index.php/p rocidingkmsi/article/view/433

Mustaqbal, M. S., Firdaus, R. F., \& Rahmadi, H. (2015). Pengujian Aplikasi Menggunakan Black Box Testing Boundary Value Analysis (Studi Kasus: Aplikasi Prediksi Kelulusan SNMPTN). Jurnal Ilmiah Teknologi Informasi Terapan, Vol. 1(No. 3), 31-36.

Pathy, S., Panda, S., \& Baboo, S. (2015). A Review on Code Coverage Analysis. International Journal of Computer Science \& Engineering Technology (IJCSET), Vol. 6(No. 10), 580-587.

Salim, M. A. (2018). Sistem Pendukung Keputusan Pemilihan Penerima Bantuan Perbaikan Rumah Menggunakan Metode Simple Additive Wieghting (SAW) Studi Kasus Kelurahan Tambelan Sampit Kota Pontianak. Jurnal SISTEMASI, Vol. 7(No. 2), 120-131. https://doi.org/https://doi.org/10.32520/stm si.v7i2.293.g124 
IN F ORMA TIKA

Jurnal Informatika, Manajemen dan Komputer, Vol. 12 No. 1, Mei 2020

eISSN : 2580-3042

pISSN : 1979-0694

Setiaji, P. (2012). Sistem Pendukung Keputusan dengan Metode Simple Additive Weighting. Jurnal Teknik Industri, Mesin, Elektro Dan Ilmu Komputer (SIMETRIS), l(1).

https://doi.org/https://doi.org/10.24176/sim et.v1i1.117

Setyawan, A., \& Sutariyani. (2013). Sistem Pendukung Keputusan Seleksi Calon Atlit Bulutangkis Berbakat PB. Djarum Kudus. Jurnal Ilmiah Go Infotech, Vol. 19(No. 1), 42-47.

Sommerville, I. (2011). Software Engineering (9th editio). Massachusetts: Pearson Education.

Sugihartono, T., Ardiansyah, D., \& Zakky, M. (2018). Implementasi Sistem Pendukung Keputusan Penerima Bantuan Rumah Tidak Layak Huni Berbasis Web. Jurnal SISFOKOM, Vol. 07(No. 01), 52-56. https://doi.org/https://doi.org/10.32736/sisf okom.v7i1.299

Sukamto, R. A., \& Shalahuddin, M. (2014). Rekayasa Perangkat Lunak: Terstruktur dan Berorientasi Objek. Bandung: Informatika.

Tridarni, L., Tasrif, E., \& Hendriyani, Y. (2015). Perancangan Sistem Pendukung Keputusan Tender Proyek di Dinas Pekerjaan Umum Solok Selatan Berbasis Web. Jurnal Vokasional Teknik Elektronika \& Informatika, Vol. 3(Nol. 1), 11-20.

UU RI No. 1 Th. 2011, 2011. Tentang Perumahan dan Kawasan Permukiman (2011). Indonesia.

Windarto, A. P. (2017). Penilaian Prestasi Kerja Karyawan PTPN III Pematangsiantar dengan Metode Simple Additive Weighting (SAW). Jurnal Riset Sistem Informasi Dan Teknik Informatika (JURASIK), Vol. 2(No. 1), 84-95.

https://doi.org/http://dx.doi.org/10.30645/ju rasik.v2i1.22.g19 